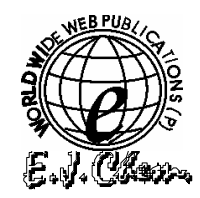

http://www.e-journals.net

\title{
Extractive Spectrophotometric Determination of Malathion in Environmental Samples using Gention Violet
}

\author{
K. M. REDDY, ${ }^{1}$ K. SUVARDHAN,${ }^{2}$ K. SURESH KUMAR, ${ }^{2}$ \\ D. REKHA, ${ }^{2}$ and P. CHIRANJEEVI ${ }^{2 *}$ \\ ${ }^{1}$ Department of Chemistry, S. V. Arts College, Tirupati - 517502. \\ ${ }^{2 *}$ Environmental Monitoring Laboratories, Department of Chemistry, \\ S.V.University, Tirupati - 517 502, India.
}

Received 21 March 2005; Accepted 10 May 2005

\begin{abstract}
A new simple and selective spectrophotometric method is developed for the determination of malathion by using Gention violet is described. The method was based on the alkaline hydrolysis of malathion in presence of sodium ethoxide to form sodium dimethyl dithiophosphate (Na-DMDTP). The Na-DMDTP was formed as an ion-pair complex with cationic dye, gention violet. The ion-pair complex was extracted into chloroform. The color of the organic layer was measured at $587 \mathrm{~nm}$. The method was applied to the determination of malathion residues in water, grain and soil samples
\end{abstract}

Key words: Malathion, Dimethyldithiophosphate (DMDTP), Gention violet, Spectrophotometry and Environmental samples.

\section{Introduction}

Malathion (O,O-dimethyl-S-(1,2-dicarboxyethyl phosphorodithioate) belongs to an organophosphorus pesticide, extensively applied on crops like banana, tobacco and citrus fruits and on vegetable crops like brinjal, beans, carrot, cauliflower, tomato, etc. to control pests like sapsucking insects and aphides of various weevils, small insects, beetles and red spider mites. It is widely used in urban population as a fog against mosquitoes by the public health authorities in India. Due to indiscriminate application which finds a way into surface water bodies through agricultural runoff and municipal waste water systems. By ingestion and inhalation malathion reaches the human system. Hence, it is inevitable to determine the residue of pesticide in water bodies, soils and vegetables to check for health hazards to human bodies. 
Many methods for the determination of malathion pesticide has been developed, such as chromatography, ${ }^{1-8}$ AAS, ${ }^{9}$ Spectrofluorometry. ${ }^{10}$ The Spectrophotometric methods are based on alkaline hydrolysis of pesticides and the resultant dimethyl dithiophosphate DMDTP is determined by metal complexation. ${ }^{1-15}$ To enhance the sensitivity of the method DMDTP is extracted with cationic dyes and determined spectrophotometrically. ${ }^{16,17}$ But these methods offer certain disadvantages such as less sensitivity, stability selectivity, high reagent consumption and interference of foreign species. Hence, it is desirable to develop a facile, rapid, accurate and sensitive spectrophotometric technique for the determination of malathion in environmental systems.

Hence, the reported extractive spectrophotometry for the determination of malathion in its formulations and in various environmental samples is more sensitive than the previously reported method available in the literature. ${ }^{10}$ Malathion was hydrolysed into sodium-dimethyl dithiophosphate [Na-DMDTP], extracted with cationic dye as an ion-pair-DMDTP into chloroform. The absorbance of organic layer was measured at $587 \mathrm{~nm}$ against reagent blank.

\section{Experimental}

\section{Materials and Methods}

Analytical grade reagents were used. Double distilled water was used throughout the experiments. All Chemicals were purchased from S.D fine Chemicals, Mumbai, India. Malathion 96.8\% technical grade and 50\% EC formulations was supplied by Northern Minerals Limited, New Delhi, India.

A HITACHI U -2001 spectrophotometer with $1.0 \mathrm{~cm}$ matched quartz cell was employed to obtain electronic spectral measurements. An ELICO digital $p H$ meter with combined glass electrode was used for the $\mathrm{pH}$ measurements.

\section{Solutions}

Standard malathion $0.4891 \mathrm{~g}$ of $96.8 \%$ technical grade solution was dissolved in $100 \mathrm{ml}$ carbontetrachloride. $10 \mathrm{ml}$ aliquot of this stock solution was diluted to $100 \mathrm{ml}$. Then a $10 \mathrm{ml}$ aliquot of this solution was further diluted to $100 \mathrm{ml}$. Working standard solutions were prepared by approximate dilution of the malathion standard solution with carbontetrachloride. Gention violet $(0.1 \%)$ was prepared by dissolving $0.1 \mathrm{~g}$ of gention violet in $100 \mathrm{ml}$ of doubly - distilled water. $7.3 \mathrm{~g}$ of hydrogen phosphate monosodium were dissolved in distilled water and diluted to $100 \mathrm{ml}$ and adjusting with $\mathrm{HCl}$ followed by ammonia for phosphate buffer solution of $\mathrm{pH}$ 6.0. Freshly cut sodium metal $(1.0 \mathrm{~g})$ was dissolved in $100 \mathrm{ml}$ ethanol for $1 \%$ sodum ethoxide solution. This solution was prepared freshly.

\section{Procedure}

Standard malathion solution (12.22 - 85.59 i g) dissolved in $\mathrm{CCl}_{4}$ was stabilized at room temperature by $1 \%$ sodium ethoxide solution to generate the corresponding sodium salt of dimethyl dithiophosphate (NaDMDTP).

$10 \mathrm{ml}$ of aliquots of the standard malathion solution (12.22 - 85.59 i g) and $2 \mathrm{ml}$ of $1 \%$ sodium ethoxide solution were taken in $100 \mathrm{ml}$ separating funnel. The mixture was swirled and allowed to stand for $30 \mathrm{~min}$. The mixture was acidified with $3 \mathrm{~N}$ nitric acid, $20 \mathrm{ml}$ of $\mathrm{CCl}_{4}$ was added and the mixture was shaken thoroughly for 2 to $3 \mathrm{~min}$ and allowed to separate. The $\mathrm{CCl}_{4}$ layer was discarded. This aqueous layer was washed with $\mathrm{CCl}_{4}$ until the $\mathrm{CCl}_{4}$ washings were colourless. To this aqueous layer, was added $10 \mathrm{ml}$ of $0.1 \%$ gention violet and $2 \mathrm{ml}$ of buffer solution of $p H 6$. The solution in the separating funnel was shaken vigorously for $1 \mathrm{~min}$. The dimethyl-dithiophosphate (DMDTP) was complexed with cationic dye Na-DMDTP - gention violet was extracted as an ion-pair into chloroform. 


\section{Determination of malathion in water samples}

The distilled tap water samples were fortified with the concentrations in the ranges of $12.22-85.59$ ppm in methanol which are given in the Table 4. The fortified water samples were extracted with chloroform. The combined extracts were washed with $0.1 \mathrm{M}$ potassium carbonate solution to break any emulsion formed during the extraction and dried over anhydrous sodium sulphate. Finally chloroform was evaporated to dryness on a steam bath and the residue was dissolved in methanol and the amount was determined using the procedure described earlier.

\section{Determination of malathion in grain samples (wheat and rice)}

The grain samples (rice and wheat) of $50 \mathrm{~g}$ each were taken in warming blender and blended for $5 \mathrm{~min}$ with $100 \mathrm{ml}$ of chloroform. The samples were fortified with different concentrations of insecticides in methanol and blended for $3 \mathrm{~min}$. Chloroform was filtered and the residue was retained. The residue was washed twice with $10 \mathrm{ml}$ of chloroform and blended for $2 \mathrm{~min}$. The chloroform extracts were evaporated on a steam bath and the residue was dissolved i methanol and the amount was determined by the procedure outlined earlier. The results were depicted in Table 4.

\section{Results and Discussion}

\section{Spectral Characteristics}

Ber's Law is dbeyed over the mddthion concentration ranges over 0.1 to $10 \mathrm{ig} \mathrm{m}^{-1}$. Limit of Quantificotion ( $L O Q$ ) were determined by toking the standard devi ation (ó) of the ld ank with respect to water and slope of calibration curve is multiplied by a factor 10 . That means, LOQ is approximately 3.3 times Limit of Detection (LOD). Normally the LOQ is slightly crosses the lower limit of Beer's law. But LOD is well below the limit of the Beer's law range. The upper limit of Beer Lambert law is determined by plot of absorbance against concentration at the value of $\ddot{e}_{\max } 587 \mathrm{~nm}$. Beyond this limit, the correlation results were really affected. Hence the measurements were excluded above these limits to keep the linear relationship. The optical characteristics and precision data are presented in Table $\mathbf{1}$.

\section{Effect of $p H$}

Effect of $\mathrm{pH}$ on complexation of dimethyl dithiophosphate with Gention violet were studied. In order to determine the optimum $\mathrm{pH}$ value corresponding to maximum intensity of the colored complex, the complexation reaction was carried out in $\mathrm{pH}$ range 4 to 8 using ELICO digital $\mathrm{pH}$ meter with combined glass electrode. The maximum color intensity was obtained at $p H 6.0$. So $p H 6.0$ was chosen as an optimum $\mathrm{pH}$ value for further studies.

\section{Effect of buffer}

Extraction of the ion - pair gention violet - NaDMTP was carried out in different buffer solutions with $p H 6$ such as sulfuric acid- potassium dihydrogen phosphate, acetic acid - sodium acetate, ammonia - hydrochloric acid and borax - hydrochloric acid. The absorbance intensity and complex stability (more than 7 days) in sulfuric acid - potassium dihydrogen phosphate of $p H 6$ is greater than in acetic acid - sodium acetate, ammonium - hydrochloride acid and borax - hydrochloride acid.

\section{Effect of solvent extraction}

Na-DMTP gention violet ion pair was studied in different organic solvents, such as chloroform, carbontetrachloride, cyclohexane, $n$-hexane. The absorbance intensity was maximum in chloroform only and no absorbance intensity was detected in cyclohexane, n-hexane and carbontetrachloride. Hence chloroform was used as the most suitable solvent for the extraction of the DMTP - gention violet ion pair. 
Table 1 Optical characteristics precision and accuracy of the method using gentian violet

\begin{tabular}{|c|c|}
\hline Concentration range $\left(\mu \mathrm{g} \mathrm{ml}^{-1}\right)$ & $0.1-10$ \\
\hline$\ddot{\mathrm{e}}_{\max }(\mathrm{nm})$ & $587 \mathrm{~nm}$ \\
\hline Stability of color (h) & more than 7 days \\
\hline Molar absorptivity $\left(1 \mathrm{~mol}^{-1} \mathrm{~cm}^{-1}\right)$ & $3.58 \cdot 10^{4}$ \\
\hline Limit of detection $\left(\mu \mathrm{g} \mathrm{ml}^{-1}\right)$ & 0.052 \\
\hline Limit of quantification & 0.2536 \\
\hline Sandell's sensitivity $\left(\mu \mathrm{g} \mathrm{cm}^{-2}\right)$ & 0.030 \\
\hline Relative standard deviation $^{\mathrm{a}}$ & 0.986 \\
\hline \multicolumn{2}{|l|}{ Regression equation $^{b}$} \\
\hline Slope $^{(\mathrm{a})}$ & $5.70 \times 10^{-2}$ \\
\hline Intercept $^{(\mathrm{b})}$ & $0.72 \times 10^{-2}$ \\
\hline Correlation coefficient & 0.9989 \\
\hline Error \% & \pm 0.0015 \\
\hline
\end{tabular}

${ }^{\mathrm{b}} \mathrm{Y}=\mathrm{ax}+\mathrm{b}$, where ' $\mathrm{x}$ ' is the concentration of malathion $\quad{ }^{\mathrm{a}} \mathrm{n}=5$.

\section{Effect of Foreign Species and other Pesticides}

The effect of foreign species of other pesticides on the determination of malathion were studied. Known amounts of a variety of foreign speecis and pesticides were added to a standard solution contaning 30 i g of mddthion in $10 \mathrm{~m}$. The solution were andysed by the proposed method The results obtained are shown in Table-2. The result shows that the foreign species and pesticides tested to not interfere in the analysis under the reported conditions. This indicates the validity of the method for the determination of malathion.

Table 2 Effect of foreign species and other pesticides on the determination of malathion residues (concentrotion of mddhion 30 i $\mathrm{g} / 10 \mathrm{ml}$ )

\begin{tabular}{cccc}
\hline Foreign species & Tolerance & Pesticide & Tolerance \\
\hline $\mathrm{Ca}^{2+}$ & 150 & phenol & 300 \\
$\mathrm{Mg}^{2+}$ & 175 & Carbaryl & 250 \\
$\mathrm{Cu}^{2+}$ & 150 & Carbofuran & 200 \\
$\mathrm{Al}^{3+}$ & 450 & DDT & 250 \\
$\mathrm{Zn}^{2+}$ & 350 & Ethylparathion & 250 \\
$\mathrm{NH}^{4+}$ & 300 & Quinalphos & 150 \\
$\mathrm{SO}_{4}{ }^{2-}$ & 250 & BMC & 300 \\
$\mathrm{Co}_{3}^{2-}$ & 250 & & \\
$\mathrm{Cl}^{-}$ & 400 & & \\
\hline
\end{tabular}




\section{Applications}

The proposed method was successfully employed for the determination of malathion in its formulation and various environmental samples. The results are summarised in Table 3 and $\mathbf{4}$. The results indicates that the present method is sensitive and selective when compared with reported method. ${ }^{10}$

Table 3 Determination of malathion in insecticidal formulations using gention violet as complexing agent

\begin{tabular}{ccc}
\hline S. No. & $50 \% \mathrm{EC}$ & 96.8 per cent \\
\hline 1. & 48.80 & 96.0 \\
2. & 48.25 & 95.43 \\
3. & 49.18 & 95.12 \\
4. & 48.70 & 95.78 \\
5. & 49.25 & 95.60 \\
Average & 48.83 & 95.58 \\
$\frac{\text { Standard deviation }}{}{ }^{\mathrm{a}}$ & 0.405 & 0.300 \\
${ }^{\mathrm{a}} \mathrm{n}=5$ & &
\end{tabular}

Table 4 Determination of malathion in various environmental samples

\begin{tabular}{|c|c|c|c|c|c|c|}
\hline \multirow{3}{*}{ Samples } & \multicolumn{3}{|c|}{ Proposed method } & \multicolumn{3}{|c|}{ Reported method ${ }^{10}$} \\
\hline & \multicolumn{3}{|c|}{$\begin{array}{l}\text { Malathion Concentrations } \\
\quad\left(\mathrm{i} \mathrm{g} \mathrm{m}^{-1}\right)\end{array}$} & \multicolumn{3}{|c|}{$\begin{array}{l}\text { Malathion Concentration } \\
\quad\left(1 \mathrm{~g} \mathrm{~m}^{-1}\right)\end{array}$} \\
\hline & $\begin{array}{l}\text { Added } \\
\left(1 \mathrm{~g} \mathrm{~m}^{-1}\right)\end{array}$ & 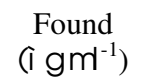 & $\begin{array}{l}\text { Recovery } \\
(\%)^{\mathrm{e}}\end{array}$ & $\begin{array}{l}\text { Added } \\
\left(\hat{~} \text { gm }^{-1}\right)\end{array}$ & $\begin{array}{l}\text { Found } \\
\left(1 \mathrm{gm}^{-1}\right)\end{array}$ & $\begin{array}{l}\text { Recovery } \\
(\%)^{\mathrm{e}}\end{array}$ \\
\hline $\begin{array}{l}\text { Synthetic } \\
\text { sample }\end{array}$ & 12.22 & 11.95 & $97.79 \pm 0.64$ & 12.22 & 11.84 & $96.8 \pm 0.41$ \\
\hline Tap water ${ }^{a}$ & 18.33 & 17.98 & $98.09+0.27$ & 18.33 & 11.86 & $97.43 \pm 0.29$ \\
\hline $\begin{array}{l}\text { Distilled } \\
\text { water }\end{array}$ & 27.49 & 27.15 & $98.76 \pm 0.45$ & 27.49 & 27.10 & $98.5 \pm 0.44$ \\
\hline Wheat $^{\mathrm{b}}$ & 41.23 & 40.86 & $99.10 \pm 0.64$ & 41.23 & 40.71 & $98.73 \pm 0.43$ \\
\hline Rice $^{c}$ & 61.84 & 61.34 & $99.19+0.38$ & 61.84 & 61.15 & $98.8 \pm 0.65$ \\
\hline Soil $^{\mathrm{d}}$ & 92.76 & 92.16 & $99.35 \pm 0.51$ & 92.76 & 91.90 & $99.07 \pm 0.69$ \\
\hline \multicolumn{7}{|c|}{$\begin{array}{l}{ }^{\mathrm{a}} \text { Collected from Laboratory, }{ }^{\mathrm{b}} \text { Collected from local market, }{ }^{\mathrm{c}} \text { Collected from local market. } \\
{ }^{\mathrm{d}} \text { Collected from Chandragiri mandal, Chittoor dist., }{ }^{\mathrm{e}} \text { Mean } \pm \text { standard deviation }\end{array}$} \\
\hline
\end{tabular}




\section{Conclusion}

The proposed method is simple, selective and highly sensitive than the spectrophotometric method available in literature. ${ }^{10}$ The statistical parameter and recovery study data clearly indicates the reproducibility and accuracy of the method. Thus, the method can be adopted as an alternative to the existing spectrophotometric methods. Hence, recommended procedure is well suited for the analysis of organophosphorus pesticides in its formulations and various environmental samples.

Fig.2 : Absorption spectrum of DETP - Gention violet ion-pair

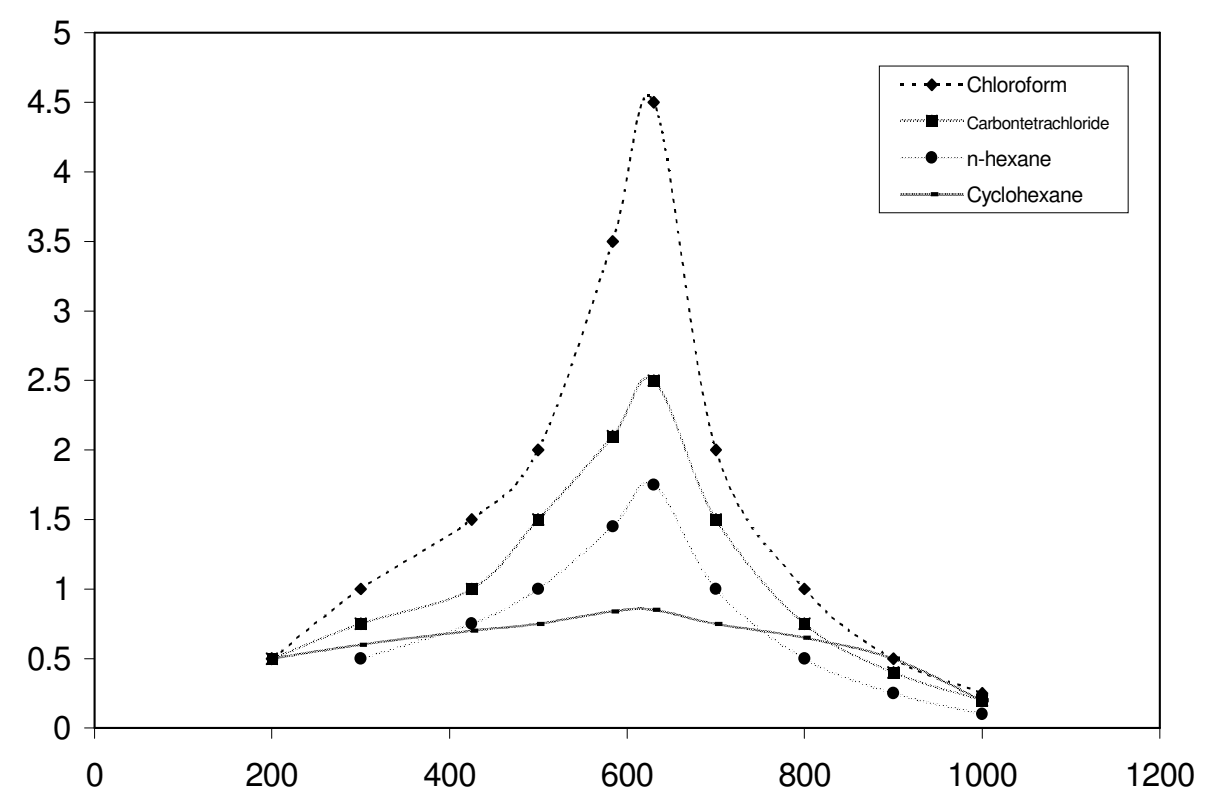

\section{References}

1. Askew J, Ruzika J H and Wheals B B, Analyst 1969, 94, 275.

2. $\quad$ Masud Z and Nasim A, Pak. J Sci Ind Res, 1972, 15, 391.

3. Masuda N, Sakurai K, Mori T and Yamada T, Mie-Ken Eisci Ken Kyusho Nenpo, 1979, $24,21$.

4. Inove Y and Fukuhara K, Shokuhin Eiseigaku Zasshi, 1974, 15, 1377.

5. $\quad$ Liu S and Niu X, Huarijing Kexue, 1982, 3, 32.

6. Simirnov V M and Gorbacheva N A. Sud Me Ekspert, 1990, 33, 32.

7. Curini M, Lagana A, Petrino B M and Russo. M V, Talenta, 1980, 37, 45.

8. Sharma V K, Jadha R K, Rao G T, Saraf A K and Chandra H, Forensic Sci. Inst, 1990, 48, 21.

9. Hernandez M J, Jimenez de Blas O, Rodriguez M V and Sanchez L E, Anal Lett, 1986, 18, 2069.

10. Rama Mohan K, Ph.D. Thesis, S. V. University, 2001.

11. Clark E R and Qazil I A, Analyst, 1979, 104, 1129.

12. Syozama M, Miyachi Y and Shakakibara J, Bun Sekikagaka, 1976, 25, 179.

13. Norris M V, Vail W A and Averell P R, J Agric Food Chem, 1967, 2, 496.

14. Hill A C, Akhtar M, Mumtaz M and Osmani J A, Analyst, 1967, 92, 496.

15. Clark E R and Qazil A, Analyst, 1980, 105, 563.

16. Seshaiah K and Mouli P, Analyst, 1987, 112, 1189.

17. Chiranjeevi P and Naidu P R, Intern J Env Studies, 1989, 33, 285. 


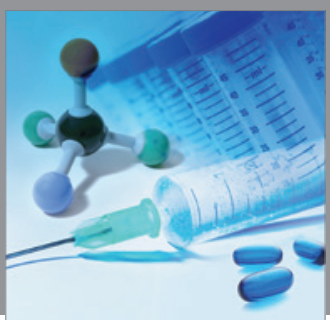

International Journal of

Medicinal Chemistry

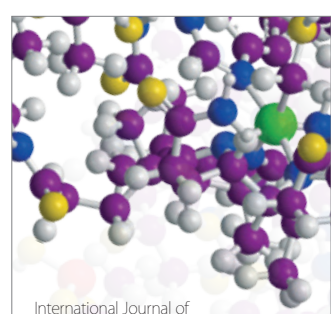

Carbohydrate Chemistry

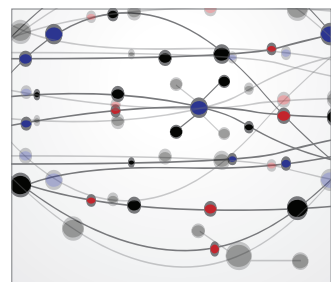

The Scientific World Journal
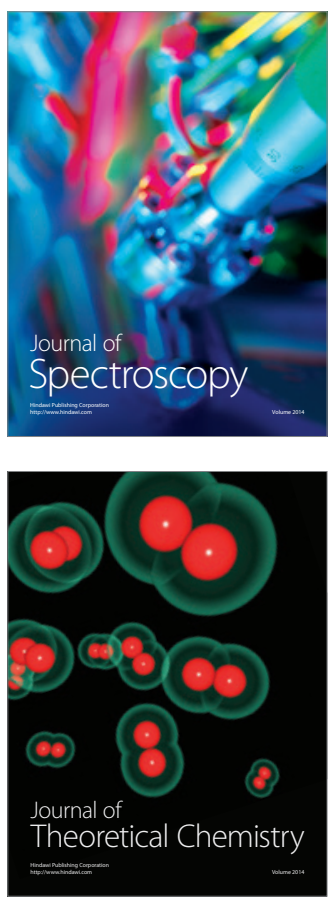
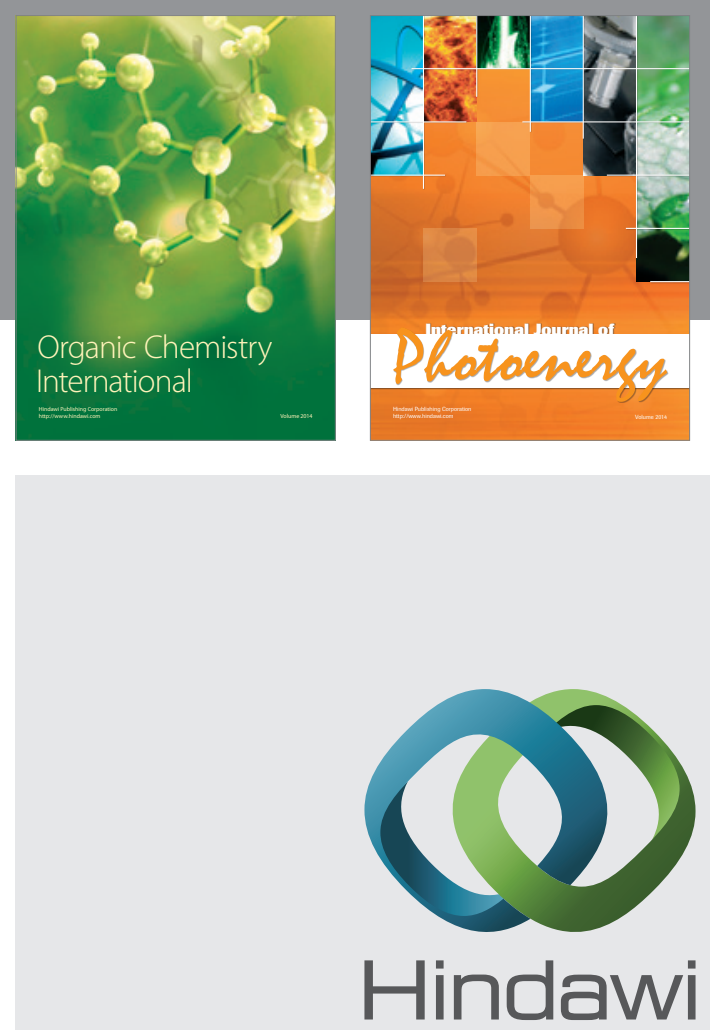

Submit your manuscripts at

http://www.hindawi.com
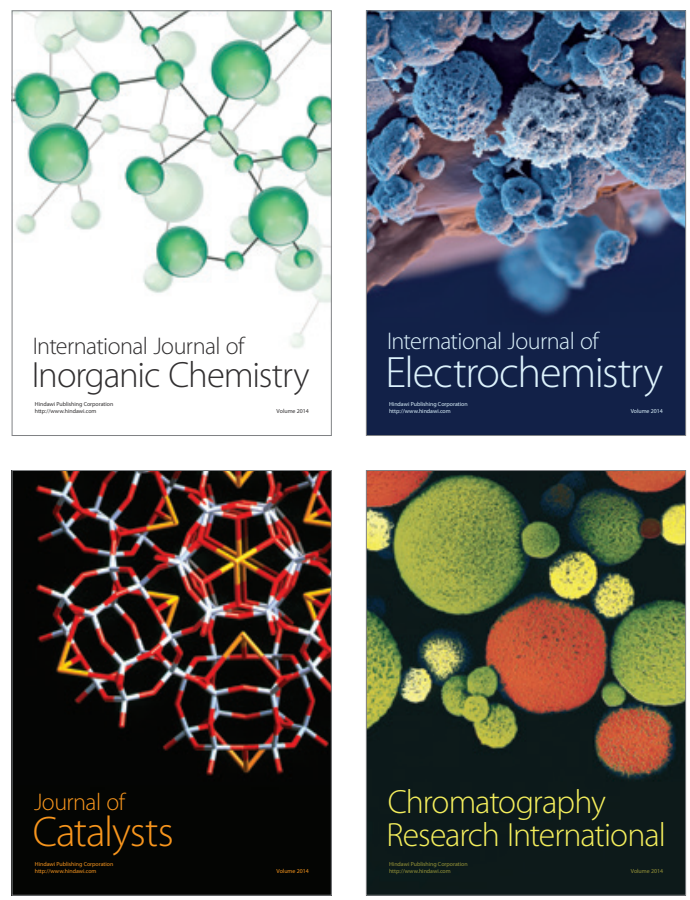
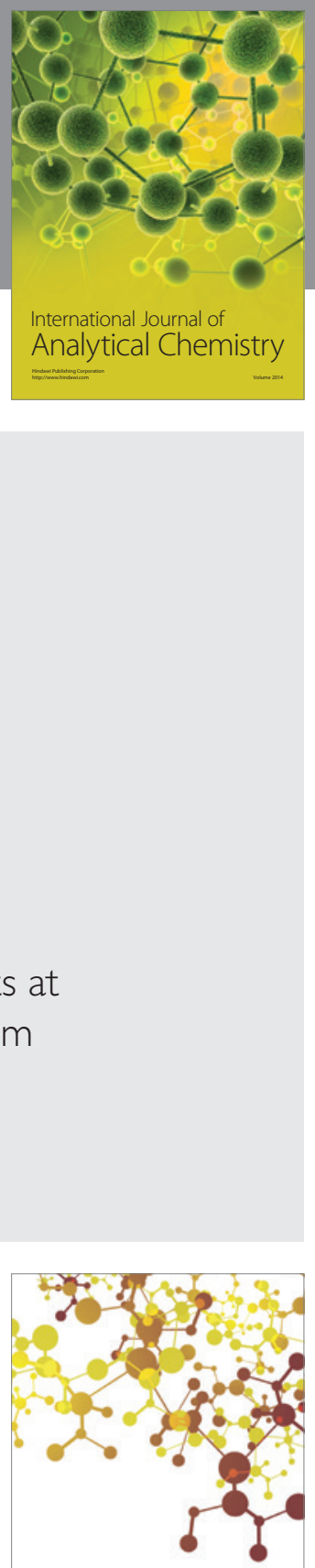

Journal of

Applied Chemistry
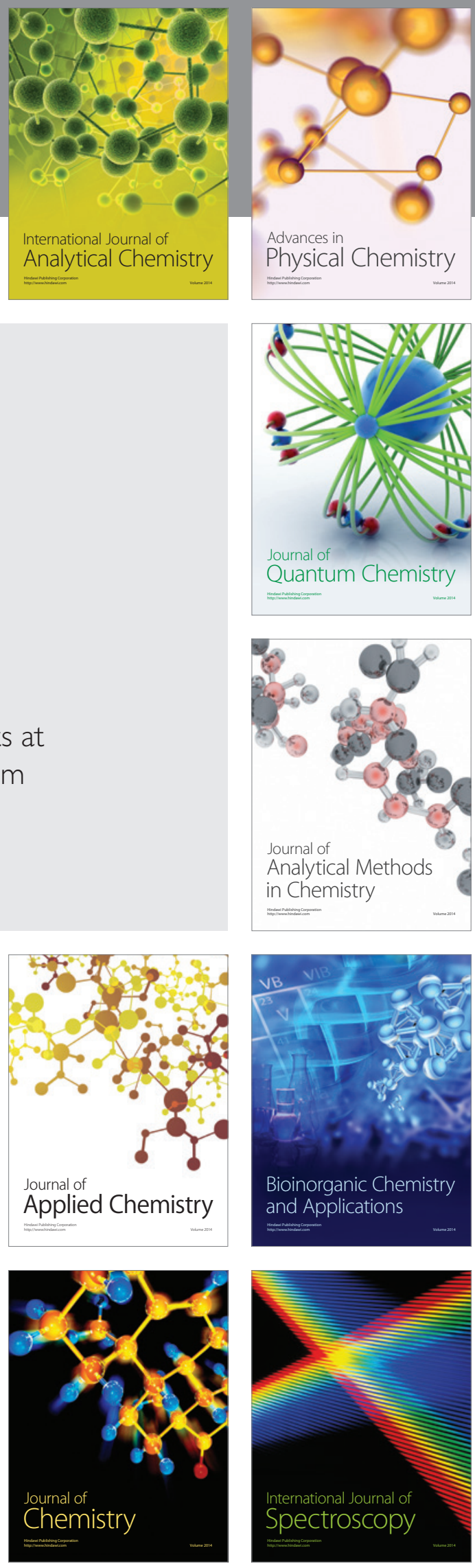